Cite this: RSC Advances, 2013, 3, 10676

Received 19th February 2013,

Accepted 13th May 2013

DOI: $10.1039 / \mathrm{c} 3 \mathrm{ra} 42105 \mathrm{~h}$

\section{Post-synthetic immobilization of palladium complexes on metal-organic frameworks - a new concept for the design of heterogeneous catalysts for Heck reactions $\dagger$}

\author{
Meike A. Gotthardt, ${ }^{a}$ Angela Beilmann, ${ }^{a}$ Roland Schoch, Julia Engelke ${ }^{a}$ \\ and Wolfgang Kleist*ac
}

www.rsc.org/advances

MIL-53- $\mathrm{NH}_{2}$ (Al) was modified in a two-step post-synthetic reaction using maleic anhydride and palladium acetate. The resulting Pd-containing frameworks were used as catalysts in Heck-type CC coupling reactions where they exhibited high conversion and selectivity. The results of leaching tests indicate that the reaction is partly catalyzed heterogeneously.

Metal-organic frameworks (MOFs) and porous coordination polymers (PCPs) have recently shown great potential as novel materials for applications in heterogeneous catalysis. ${ }^{1}$ Various strategies have been presented to utilize (i) transition metal nanoparticles inside the pore structure, ${ }^{2}$ (ii) unsaturated framework metal sites, ${ }^{3}$ (iii) framework metal centers with defect sites, ${ }^{3 d}$ or (iv) functional side groups of the organic linker molecules ${ }^{4}$ as potential active sites for catalytic transformations. The first two of them have already been applied for the design of Pd catalysts for CC coupling reactions: MOF-based catalysts, which are built from Pd ions and organic linker molecules, have been reported. ${ }^{3 a, 5}$ $\left[\mathrm{Pd}(2-\text { pymo })_{2}\right]_{n} \cdot 3 \mathrm{H}_{2} \mathrm{O}$ has successfully been used as a catalyst for Suzuki-Miyaura coupling reactions of $p$-bromoanisole and phenyl boronic acid. ${ }^{3 a}$ Due to the fact that this catalyst contains isolated metal centers it acts as a very effective palladium reservoir for slow release of active species, although the very high Pd content of the catalyst may be seen as a drawback.

In addition, also Pd nanoparticles have successfully been introduced in the pore system of various well-known framework compounds, ${ }^{2 a}$ like MOF-5, ${ }^{2 b}$ IRMOF- $3,{ }^{6}$ MIL-53 ${ }^{2 d}$ and MIL-101 ${ }^{7}$ via different routes (e.g. liquid phase infiltration, vapor phase deposition, etc). Beside other catalytic applications, which include

${ }^{a}$ Karlsruhe Institute of Technology (KIT), Institute for Chemical Technology and Polymer Chemistry, Engesserstr. 20, D-76128 Karlsruhe, Germany.

E-mail: wolfgang.kleist@kit.edu; Fax: +49721608 44820; Tel: +49 72160847989

${ }^{b}$ TU Kaiserslautern, Fachbereich Chemie, Erwin-Schrödinger-Str. 54, D-67663 Kaiserslautern, Germany

${ }^{c}$ Karlsruhe Institute of Technology (KIT), Institute of Catalysis Research and Technology, Hermann-von-Helmholtz-Platz 1, D-76344 Eggenstein-Leopoldshafen, Germany

$\dagger$ Electronic supplementary information (ESI) available: Experimental details, nitrogen physisorption, FT-IR spectroscopy, X-ray absorption spectroscopy. See DOI: $10.1039 / \mathrm{c} 3 \mathrm{ra} 42105 \mathrm{~h}$ hydrogenation reactions, ${ }^{5}$ some of the resulting catalysts have already been studied in Heck, ${ }^{2 d, 8}$ Suzuki-Miyaura, ${ }^{2 c}$ and Sonogashira $^{2 b}$ reactions, mainly involving aryl iodides and bromides, where they showed reasonable activity and productivity.

The mechanism of these Pd catalyzed coupling reactions in the presence of supported catalyst systems has been extensively studied in the last years and it is well-accepted that the catalytically active species are dissolved Pd complexes or clusters which are generated in situ during the reaction. ${ }^{9}$ Although in some cases a truly heterogeneous reaction pathway is claimed for $\mathrm{Pd} / \mathrm{MOF}$ systems, one should note that virtually negligible amounts of dissolved Pd (below the detection limit of standard analysis techniques) may be sufficient for the activation of highly reactive substrates, such as aryl iodides or activated bromides. ${ }^{10}$ Consequently, applications of Pd nanoparticles inside the pores of metal-organic frameworks in liquid phase coupling reactions may be restricted.

In the present work we report an unprecedented strategy for the design of Pd/MOF catalysts, namely the immobilization of Pd complexes via post-synthetic modification ${ }^{11}$ of $\mathrm{MIL}-53-\mathrm{NH}_{2}(\mathrm{Al})^{12}$ with maleic anhydride and Pd acetate. This route allows the introduction of targeted amounts of well-defined anchored Pd complexes, whose structure and activity are expected to be similar to the highly active homogeneous species that are formed in situ in conventional catalyst systems. Hence, leaching studies should be suitable to elucidate if the reaction mechanism is either analogous to conventional supported catalysts or contributions of truly heterogeneous species can be found. Previously, immobilization of Pd(II) complexes has been reported as a concept for the preparation of catalysts for Heck reactions using mesoporous silica as support. ${ }^{13}$

The catalysts were synthesized via a two-step post-synthetic modification reaction of $\mathrm{MIL}-53-\mathrm{NH}_{2}(\mathrm{Al})$. First maleic anhydride reacted with the amine groups of $\mathrm{MIL}-53-\mathrm{NH}_{2}(\mathrm{Al})$ resulting in the formation of a side chain which may act as a chelating ligand facilitating the subsequent immobilization of $\mathrm{Pd}(\mathrm{II})$ ions (Scheme 1).

Varying amounts of maleic anhydride (2-10 eq relating to the number of amine groups) and palladium acetate (0.25-1.5 eq 


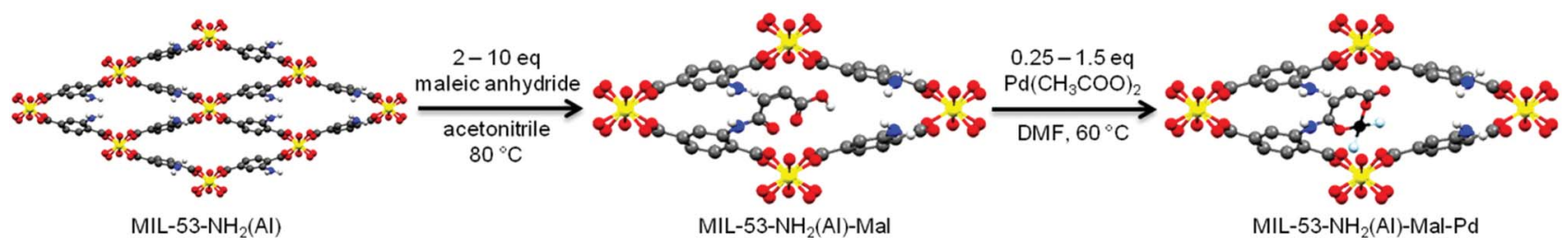

Scheme 1 Post-synthetic modification of MIL-53-NH $(\mathrm{Al})$.

based on the number of modified side chains) were applied to optimize the modification. The materials were characterized after each step using powder X-ray diffraction (XRD), FT-IR spectroscopy and nitrogen physisorption measurements (BET). The Pd containing frameworks were in addition analyzed by X-ray absorption spectroscopy (XAS) ${ }^{14}$ and atomic absorption spectroscopy (AAS).

The X-ray diffraction patterns of the modified samples (Fig. 1) proved that the structure of MIL-53- $\mathrm{NH}_{2}(\mathrm{Al})$ (monoclinic, space group Cc) ${ }^{12 a}$ is retained throughout the modification process. All signals corresponding to lattice distances perpendicular to the pores $(h, k, l=2,0,0$ and $4,0,0)$ remain at the same $2 \Theta$ values $\left(9.28^{\circ}\right.$ and $18.62^{\circ}$, respectively) while a shift can be seen for all other peaks. This observation is explained by the so called breathing effect of MIL-53- $\mathrm{NH}_{2}(\mathrm{Al})$, which describes the fact that the framework can change its pore geometry depending on the substrate or guest molecules inside the pores. ${ }^{12 a}$ The observed peak shift is, thus, a clear indication for the successful postsynthetic modification of the amine groups in MIL-53- $\mathrm{NH}_{2}(\mathrm{Al})$.

Successful amide formation is also indicated by the decreasing intensity of the $\mathrm{N}-\mathrm{H}$ stretching vibration $\left(v=3498 \mathrm{~cm}^{-1}\right.$ and $v=$ $3387 \mathrm{~cm}^{-1}$ ) in the FT-IR spectra (see ESIt). Moreover an additional band around $1700 \mathrm{~cm}^{-1}$ is observed for MIL-53- $\mathrm{NH}_{2}(\mathrm{Al})-\mathrm{Mal}$ arising from the $\mathrm{C}=\mathrm{O}$ vibrations of the inserted carbonyl groups at the side chain. No residual maleic anhydride was found.

Nitrogen physisorption measurements (see ESI†) of the samples modified with maleic anhydride show a drastic decrease of the surface area $\left(155 \mathrm{~m}^{2} \mathrm{~g}^{-1}\right)$ compared to that of pure MIL-53-NH $(\mathrm{Al})$ $\left(980 \mathrm{~m}^{2} \mathrm{~g}^{-1}\right)$ which again proves the presence of the amide.

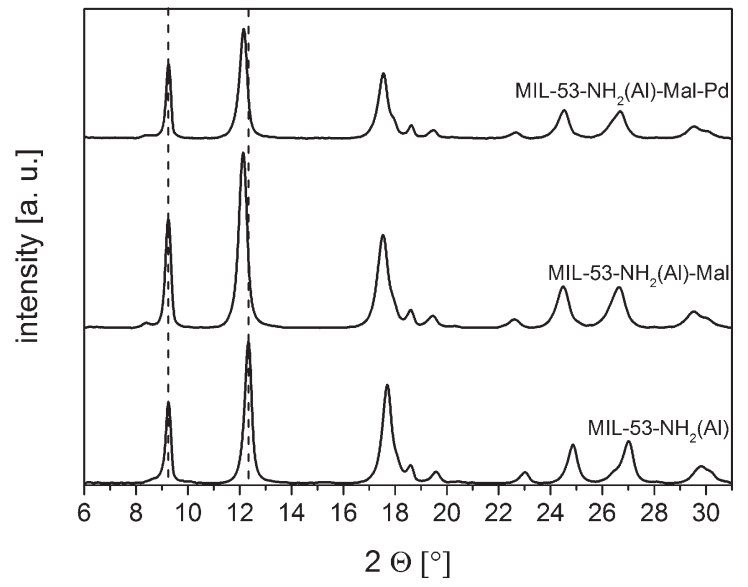

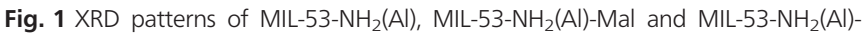
Mal-Pd.
Measurements of different Pd containing frameworks show that the surface area decreased with increasing precursor amount (90$\left.65 \mathrm{~m}^{2} \mathrm{~g}^{-1}\right)$.

Atomic absorption spectroscopy of the digested samples revealed that the Pd content of the different frameworks is similar (2.1-2.4 wt\%) independent of the precursor amount (0.25-1.5 eq) used for the modification. This observation in combination with the nitrogen physisorption results led to the hypothesis that high precursor amounts cause the formation of Pd nanoparticles inside the pores whereas low precursor amounts resulted in the desired immobilization of Pd(II) species.

The hypothesis was further corroborated using X-ray absorption spectroscopy (XAS) (Fig. 2 and ESI†) at the Pd K edge. It became obvious that the Pd species inside the framework are indeed different although the Pd content is nearly the same. Whereas low precursor amounts (0.25 and 0.5 eq) resulted in the targeted immobilization of $\mathrm{Pd}(\mathrm{II})$ in oxidized form (MIL-53$\mathrm{NH}_{2}$ (Al)-Mal-Pd), higher precursor amounts (1.0 and 1.5 eq)
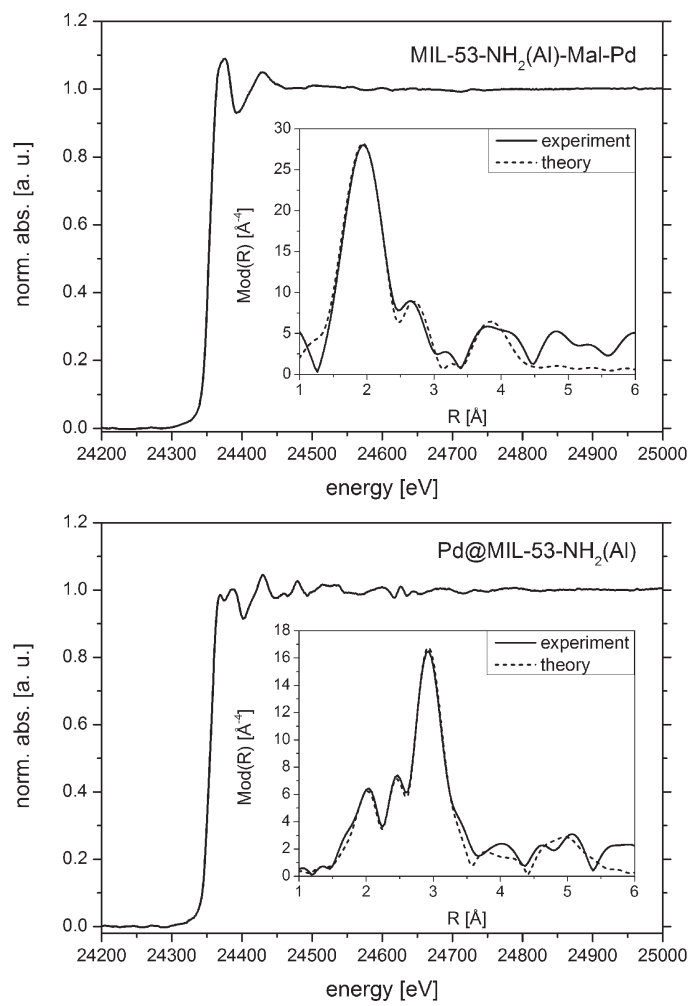

Fig. 2 Normalized and Fourier-transformed EXAFS spectra of MIL-53-NH $\mathrm{Pd}$ and Pd@MIL-53-NH $\mathrm{N}_{2}(\mathrm{Al})$. 


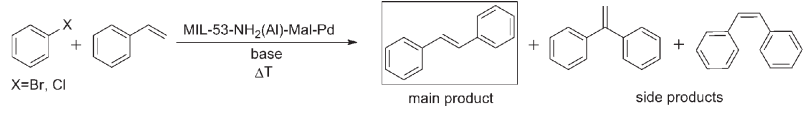

Scheme 2 Heck coupling of aryl halides and styrene.

mainly led to the additional formation of metallic Pd nanoparticles $^{15}$ (Pd@MIL-53-NH $\mathrm{NH}_{2}(\mathrm{Al})$ ). For MIL-53-NH $\mathrm{NH}_{2}(\mathrm{Al})-\mathrm{Mal}-\mathrm{Pd} 3.9$ oxygen atoms could be fitted in the first shell at a distance of $2.008 \AA$ which is in good agreement with immobilized $\mathrm{Pd}(\mathrm{II})$ complexes in fourfold coordination. In addition no palladium shells could be fitted. In contrast, for Pd@MIL-53- $\mathrm{NH}_{2}(\mathrm{Al})$ only 1.3 oxygen atoms could be fitted at $2.035 \AA$ while three palladium shells were found at 2.740, 3.794 and $4.750 \AA$, which corresponds well to distances in metallic palladium. Thus, high precursor amounts seem to favor the formation of Pd nanoparticles with only minor contributions of the immobilized complexes. The size of the Pd nanoparticles in Pd@MIL-53- $\mathrm{NH}_{2}(\mathrm{Al})$ can be calculated from EXAFS data. Mainly Pd clusters with 10-15 atoms were found but it seems that there are also minor contributions of bigger clusters with up to about $100 \mathrm{Pd}$ atoms (see ESI $\dagger$ ).

Since Pd containing materials are known to be highly active in CC coupling reactions, we applied the modified frameworks MIL53- $\mathrm{NH}_{2}(\mathrm{Al})-\mathrm{Mal}-\mathrm{Pd}$ and $\mathrm{Pd} @ \mathrm{MIL}-53-\mathrm{NH}_{2}(\mathrm{Al})$ as heterogeneous catalysts in a Heck reaction of styrene with aryl halides (Scheme 2). For parameter optimization the catalyst with immobilized Pd(II) complexes (MIL-53- $\mathrm{NH}_{2}(\mathrm{Al})-\mathrm{Mal}-\mathrm{Pd}$ ) was chosen. The new catalyst materials were further compared to a conventional heterogeneous $\left(\mathrm{Pd} @ \mathrm{Al}_{2} \mathrm{O}_{3}\right)$ as well as a homogeneous catalyst $(\mathrm{Pd}(\mathrm{II})$ acetate).

First the catalytic activity of MIL-53- $\mathrm{NH}_{2}(\mathrm{Al})-\mathrm{Mal}-\mathrm{Pd}$ was probed in the reaction of bromobenzene with styrene under standard conditions known from literature $\left(140{ }^{\circ} \mathrm{C}\right.$, NMP, sodium acetate) ${ }^{9 b}$ Under those conditions nearly full conversion and a selectivity of $90 \%$ were achieved after $3 \mathrm{~h}$ (Table 1 , entry 1 ). Then the activity of the new catalyst was tested in the coupling of chlorobenzene and styrene. Similar to literature reports ${ }^{9 b}$ calcium hydroxide turned out to be a better base compared to sodium acetate. For chlorobenzene higher temperatures $\left(160{ }^{\circ} \mathrm{C}\right)$ and longer reaction times $(6 \mathrm{~h})$ were necessary, because the activation of the $\mathrm{C}-\mathrm{Cl}$

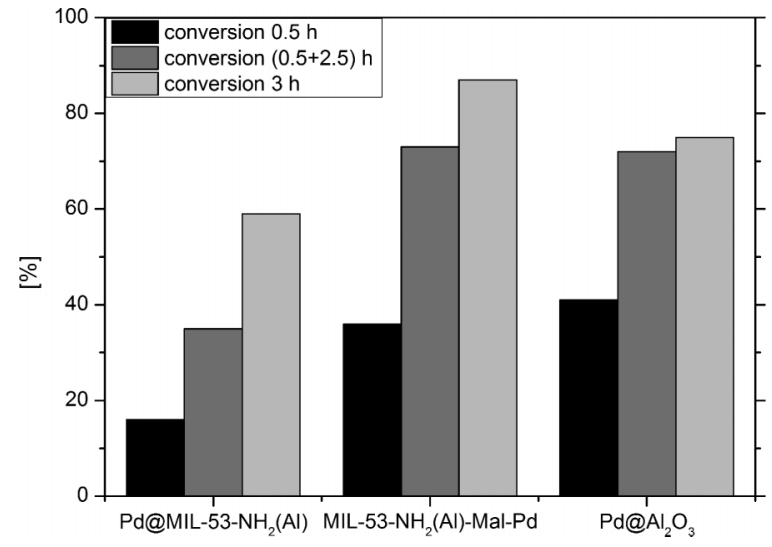

Fig. 3 Results of the hot filtration test. Reaction conditions: NMP, $10 \mathrm{mmol}$ bromobenzene, $15 \mathrm{mmol}$ styrene, $12 \mathrm{mmol}$ potassium acetate, $0.01 \mathrm{~mol} \%$ catalyst, $140{ }^{\circ} \mathrm{C}$.

bond is more demanding compared to the $\mathrm{C}-\mathrm{Br}$ bond due to higher bond energy. To further increase the stilbene yield, tetrabutylammonium bromide (TBAB) was added as a promoting agent. Under those optimized conditions a conversion of $21 \%$ and a yield of $17 \%$ in respect to trans-stilbene were reached using the framework MIL-53- $\mathrm{NH}_{2}$ (Al)-Mal-Pd (Table 1, entry 8). Under the same conditions a considerably lower conversion (11\%) was achieved using the conventional catalyst $\mathrm{Pd} @ \mathrm{Al}_{2} \mathrm{O}_{3}$ (Table 1, entry 9). The homogeneously dissolved Pd salt reached only a slightly higher conversion of $33 \%$ (Table 1 , entry 10 ).

To gather information about the reaction mechanism and the leaching behavior of the catalyst, a hot filtration test was conducted using MIL-53- $\mathrm{NH}_{2}(\mathrm{Al})-\mathrm{Mal}-\mathrm{Pd}, \mathrm{Pd} @ \mathrm{MIL}-53-\mathrm{NH}_{2}(\mathrm{Al})$ and $\mathrm{Pd} @ \mathrm{Al}_{2} \mathrm{O}_{3}$ as catalyst materials. The catalysts were removed from the reaction mixture after half an hour and the reaction was resumed for another $2.5 \mathrm{~h}$ (Fig. 3).

Atomic absorption spectroscopy (Table 2) revealed that the leaching for the catalyst with immobilized Pd complexes (1.7\%) is significantly lower than that of the two catalysts containing nanoparticles (2.8\% and 2.9\%, respectively). Nonetheless, MIL-53$\mathrm{NH}_{2}(\mathrm{Al})-\mathrm{Mal}-\mathrm{Pd}$ proved to be the most active catalyst in the coupling reaction of bromobenzene and styrene resulting in a conversion of $87 \%$ and a selectivity of $92 \%$ after $3 \mathrm{~h}$ at $140{ }^{\circ} \mathrm{C}$.

Table 1 Catalytic results

\begin{tabular}{|c|c|c|c|c|c|c|c|}
\hline Entry & Catalyst & Substrate & Temp. $\left[{ }^{\circ} \mathrm{C}\right]$ & Additives (TBAB) & Conv. $[\%]$ & Yield [\%] & TON \\
\hline 1 & MIL-Pd ${ }^{a}$ & $\mathrm{BrBz}^{b}$ & 140 & - & 96 & 88 & 8236 \\
\hline 2 & MIL-Pd $^{a}$ & $\mathrm{BrBz}^{b}$ & 160 & - & 98 & 88 & 8370 \\
\hline 3 & MIL-Pd ${ }^{a}$ & $\mathrm{ClBz}^{c}$ & 140 & - & 1 & 0 & 12 \\
\hline 4 & MIL-Pd ${ }^{a}$ & $\mathrm{ClBz}^{c}$ & 140 & $2 \mathrm{mmol}$ & 4 & 3 & 375 \\
\hline 5 & MIL-Pd ${ }^{a}$ & $\mathrm{ClBz}^{c}$ & 140 & $4 \mathrm{mmol}$ & 7 & 6 & 683 \\
\hline 6 & MIL-Pd ${ }^{a}$ & $\mathrm{ClBz}^{c}$ & 140 & $6 \mathrm{mmol}$ & 15 & 11 & 1121 \\
\hline 7 & MIL-Pd ${ }^{a}$ & $\mathrm{ClBz}^{c}$ & 160 & $6 \mathrm{mmol}$ & 7 & 6 & 610 \\
\hline 8 & MIL-Pd $^{a}$ & $\mathrm{ClBz}^{d}$ & 160 & $6 \mathrm{mmol}$ & 22 & 17 & 1740 \\
\hline 9 & $\mathrm{Pd} @ \mathrm{Al}_{2} \mathrm{O}_{3}$ & $\mathrm{ClBz}^{d}$ & 160 & $6 \mathrm{mmol}$ & 11 & 9 & 905 \\
\hline 10 & Pd(II)acetate & $\mathrm{ClBz}^{d}$ & 160 & $6 \mathrm{mmol}$ & 33 & 28 & 3102 \\
\hline
\end{tabular}

${ }^{a}$ MIL-53-NH $(\mathrm{Al})$-Mal-Pd. ${ }^{b}$ Bromobenzene, sodium acetate, 3 h. ${ }^{c}$ Chlorobenzene, sodium acetate, 6 h. ${ }^{d}$ Chlorobenzene, calcium hydroxide, 6 
Table 2 Results of the hot filtration tests and Pd leaching determined by atomic absorption spectroscopy

\begin{tabular}{|c|c|c|c|}
\hline Catalyst & Conv. hot filtration test ${ }^{a}[\%]$ & Conv. with catalyst ${ }^{b}[\%]$ & $\operatorname{Pd~leaching~}^{c}[\%]$ \\
\hline Pd@MIL-53--NH & 35 & 59 & 2.8 \\
\hline MIL-53-NH ${ }_{2}(\mathrm{Al})-\mathrm{Mal}-\mathrm{Pd}$ & 73 & 87 & 1.7 \\
\hline $\mathrm{Pd} @ \mathrm{Al}_{2} \mathrm{O}_{3}$ & 72 & 75 & 2.9 \\
\hline
\end{tabular}

${ }^{a}$ After $3 \mathrm{~h}$, catalyst was removed after $0.5 \mathrm{~h} .{ }^{b}$ After $3 \mathrm{~h}$ with the catalyst. ${ }^{c}$ Percentage of total Pd amount that was found in solution.

Using $\mathrm{Pd} @ \mathrm{Al}_{2} \mathrm{O}_{3}$ resulted in the same conversion after $3 \mathrm{~h}$ independent of the catalyst being retained or filtered off (Fig. 3). This was not the case for the framework based catalysts where the conversion after catalyst filtration was considerably lower (Fig. 3). These results indicate that in the presence of the immobilized Pd complexes contributions of a truly heterogeneous reaction pathway are found in addition to the well-accepted "quasi-homogeneous" pathway ${ }^{9}$ that is exclusively responsible for the activity of the conventional catalysts.

MIL-53- $\mathrm{NH}_{2}(\mathrm{Al})-\mathrm{Mal}-\mathrm{Pd}$ was reused three times in the coupling of bromobenzene and styrene at $140{ }^{\circ} \mathrm{C}$. It was observed that the conversion of the second and third run were significantly lower $(22 \%)$ than that of the first run (about $80 \%$ ). Apparently the reusability of the catalyst is hampered under the given reaction conditions. The activity loss might be ascribed to blocking of the pores by the base (NaOAc), which is not completely dissolved in the reaction mixture.

In conclusion, well-defined Pd(II) complexes could successfully be immobilized in the side chains of the organic linker molecules of MIL-53- $\mathrm{NH}_{2}(\mathrm{Al})$ via post-synthetic modification which was confirmed by XAS, XRD, FT-IR and nitrogen physisorption. The Pd-containing frameworks proved to be highly active in the Hecktype coupling reaction of aryl halides (namely bromo- and chlorobenzene) with styrene. The results indicate that in the case of MIL-53- $\mathrm{NH}_{2}(\mathrm{Al})-\mathrm{Mal}-\mathrm{Pd}$ immobilized Pd complexes contribute to the reaction mechanism via a truly heterogeneous pathway, while for conventional supported catalysts exclusively homogeneously dissolved species are active. Moreover, the leaching found for the new catalyst material is significantly lower compared to conventional catalysts.

We thank Hasylab at DESY for providing beamtime at beamline X1 and Dr Michael Murphy for his support. This work was supported by the KIT competence portfolio "Matter and Materials -Applied and New Materials".

\section{Notes and references}

1 (a) A. Dhakshinamoorthy, M. Alvaro and H. Garcia, Chem. Commun., 2012, 48, 11275; (b) S. T. Meek, J. A. Greathouse and M. D. Allendorf, Adv. Mater., 2011, 23, 249; (c) J. Lee, O. K. Farha, J. Roberts, K. A. Scheidt, S. T. Nguyen and J. T. Hupp, Chem. Soc. Rev., 2009, 38, 1450.

2 (a) M. Meilikhov, K. Yusenko, D. Esken, S. Turner, G. Van Tendeloo and R. A. Fischer, Eur. J. Inorg. Chem., 2010, 3701; (b) S. Gao, N. Zhao, M. Shu and S. Che, Appl. Catal., A, 2010, 388, 196; (c) Y. Huang, Z. Zheng, T. Liu, J. Lü, Z. Lin, H. Li and R. Cao, Catal. Commun., 2011, 14, 27; (d) Y. Huang, S. Gao,
T. Liu, J. Lü, X. Lin, H. Li and R. Cao, ChemPlusChem, 2012, 77, 106; (e) A. Dhakshinamoorthy and H. Garcia, Chem. Soc. Rev., 2012, 41, 5262.

3 (a) F. X. Llabrés i Xamena, A. Abad, A. Corma and H. Garcia, J. Catal., 2007, 250, 294; (b) L. Alearts, E. Séguin, H. Poelman, F. Thibault-Starzyk, P. A. Jacobs and D. E. De Vos, Chem.-Eur. J., 2006, 12, 7353; (c) K. Schlichte, T. Kratzke and S. Kaskel, Microporous Mesoporous Mater., 2004, 73, 81; (d) S. Marx, W. Kleist and A. Baiker, J. Catal., 2011, 281, 76.

4 (a) J. Gascon, U. Akray, M. D. Hernandez-Alonso, G. P. M. van Klink and F. Kapteijn, J. Catal., 2009, 261, 75; (b) M. J. Ingleson, J. P. Barrio, J.-B. Guilbaud, Y. Z. Khimyak and M. J. Rosseinsky, Chem. Commun., 2008, 2680.

5 S. Schuster, E. Klemm and M. Bauer, Chem.-Eur. J., 2012, 18, 15831.

6 V. I. Isaeva, O. P. Tkachenko, E. V. Afonina, L. M. Kozlova, G. I. Kapustin, W. Grünert, S. E. Solov'eva, I. S. Antipin and L. M. Kustov, Microporous Mesoporous Mater., 2013, 166, 167.

7 J. Hermannsdörfer and R. Kempe, Chem.-Eur. J., 2011, 17, 8071. 8 S.-N. Kim, S.-T. Yang, J. Kim, J.-E. Park and W.-S. Ahn, CrystEngComm, 2012, 14, 4142.

9 (a) F. Zhao, M. Shirai, Y. Ikushima and M. Arai, J. Mol. Catal. A: Chem., 2002, 180, 211; (b) S. S. Pröckl, W. Kleist, M. A. Gruber and K. Köhler, Angew. Chem., Int. Ed., 2004, 43, 1881; (c) N. T. S. Phan, M. Van Der Sluys and C. W. Jones, Adv. Synth. Catal., 2006, 348, 609; (d) K. Köhler, W. Kleist and S. S. Pröckl, Inorg. Chem., 2007, 46, 1876; (e) S. Reimann, J. Stötzel, R. Frahm, W. Kleist, J.-D. Grunwaldt and A. Baiker, J. Am. Chem. Soc., 2011, 133, 3921; (f) A. F. Schmidt and A. A. Kurokhtina, Kinet. Catal., 2012, 53, 714.

10 W. Kleist, S. S. Pröckl and K. Köhler, Catal. Lett., 2008, 125, 197.

11 (a) A. D. Burrows, C. G. Frost, M. F. Mahon and C. Richardson, Angew. Chem., Int. Ed., 2008, 47, 8482; (b) Z. Wang and S. M. Cohen, Chem. Soc. Rev., 2009, 38, 1315; (c) K. K. Tanabe and S. M. Cohen, Chem. Soc. Rev., 2011, 40, 498; (d) A. D. Burrows and L. L. Keenan, CrystEngComm, 2012, 14, 4112.

12 (a) T. Loiseau, C. Serre, C. Huguenard, G. Fink, F. Taulelle, M. Henry, T. Bataille and G. Férey, Chem.-Eur. J., 2004, 10, 1373; (b) T. Ahnfeldt, D. Gunzelmann, T. Loiseau, D. Hirsemann, J. R. Senker, G. Férey and N. Stock, Inorg. Chem., 2009, 48, 3057.

13 K.-i. Shimizu, S. Koizumi, T. Hatamachi, H. Yoshida, S. Komai, T. Kodama and Y. Kitayama, J. Catal., 2004, 228, 141.

14 (a) M. Bauer and H. Bertagnolli, in Methods in Physical Chemistry, Wiley-VCH Verlag GmbH \& Co. KGaA, 2012, p. 231; (b) V. Guillerm, S. Gross, C. Serre, T. Devic, M. Bauer and G. Férey, Chem. Commun., 2010, 46, 767.

15 M. Bauer, R. Schoch, L. Shao, B. Zhang, A. Knop-Gericke, M. Willinger, R. Schlögl and D. Teschner, J. Phys. Chem. C, 2012, 116, 22375. 